\title{
Improving Outcomes of Percutaneous Coronary Intervention through the Application of Guidelines and Benchmarking: Reduction of Major Bleeding and Blood Transfusion as a Model
}

\author{
Stanley J. Chetcuti, M.D., Paul M. Grossman, M.D., Eva M. Kline-Rogers, R.N., M.S., Cecelia Montoye, R.n., M.n., \\ Dean Smith, M.S., PH.D., Mauro Moscucci, M.D.
}

University of Michigan Cardiovascular Center; *St. Joseph Mercy Hospital, Ann Arbor, Michigan, USA

\begin{abstract}
Summary
Blood transfusions are a relatively common occurrence after performing any percutaneous coronary intervention (PCI). Although guidelines for blood transfusion have been previously specified, retrospective analysis of transfusion practices have suggested that these guidelines are rarely applied. We describe a model for the application of a continuous quality improvement program including benchmarking and available guidelines for blood transfusion, aimed toward reducing transfusion rates among patients undergoing PCI.
\end{abstract}

Key words: transfusion, ischemia, bleeding, quality improvement

Clin. Cardiol. 2007; 30 (Suppl. II): II-44-II-48.

(C) 2007 Wiley Periodicals, Inc.

\section{Introduction}

Advancements in pharmacotherapy and in catheter technology have resulted in improved outcomes from acute coronary syndromes (ACS) and in increased safety and success rates of percutaneous coronary intervention

Address for reprints:

Mauro Moscucci, M.D.

University of Michigan Cardiovascular Center

1500 E Medical Center Drive, SPC 5869

Ann Arbor, MI 48109-5869, USA

e-mail: moscucci@umich.edu

Received: June 18, 2007

Accepted: June 19, 2007

Published online in Wiley InterScience

(www.interscience.wiley.com).

DOI: $10.1002 / \mathrm{clc} .20230$

(C) 2007 Wiley Periodicals, Inc.
(PCI). Unfortunately, development of major bleeding continues to be the most frequent noncardiac complication of $\mathrm{ACS}^{1-3}$ (Fig. 1) and of PCI. ${ }^{4}$ Importantly, although it is unquestionable that the safety of blood supply has improved significantly, blood transfusion is still associated with a small risk of blood-borne infections. ${ }^{5,6}$ In addition, recent studies have suggested a relationship between major bleeding and an increased risk of inhospital death among patients with ACS (Fig. 2), ${ }^{7}$ and a relationship between blood transfusion and an increased risk of adverse outcomes and in-hospital mortality among critically ill patients, ${ }^{8}$ patients with ACS ${ }^{7,9}$ and patients undergoing PCI. ${ }^{10}$

The pathophysiology surrounding the relationship between blood transfusion and an increased risk of death remains unclear. In general, blood transfusions are associated with a small, though not insignificant, risk of viral transmission, ${ }^{5}$ bacterial contamination, and hemolytic reactions. ${ }^{11}$ In addition, some studies have shown a relationship between blood transfusion and an increased risk of acute respiratory distress syndrome in critically ill patients. ${ }^{12}$ Other studies have shown a significantly higher rate of nosocomial infections among critical care patients transfused with red blood cells when compared with patients who did not received a blood transfusion. ${ }^{13}$ Postulated mechanisms surrounding these increased risks include a systemic inflammatory response triggered by blood transfusion, nonspecific immunosuppression mediated by a graft-versus-host reaction, by an increase in T-lymphocyte suppressor and natural killer cell function, and by a decrease in activity of monocytes and macrophages. ${ }^{11}$ In addition, it has been suggested that tissue hypoxemia mediated by occlusion of the microvasculature might play an important role in the adverse effects of blood transfusion in critically ill patients.

\section{Risk Factors for Major Bleeding}

Several studies have evaluated risk factors associated with an increased risk of major bleeding in patients 


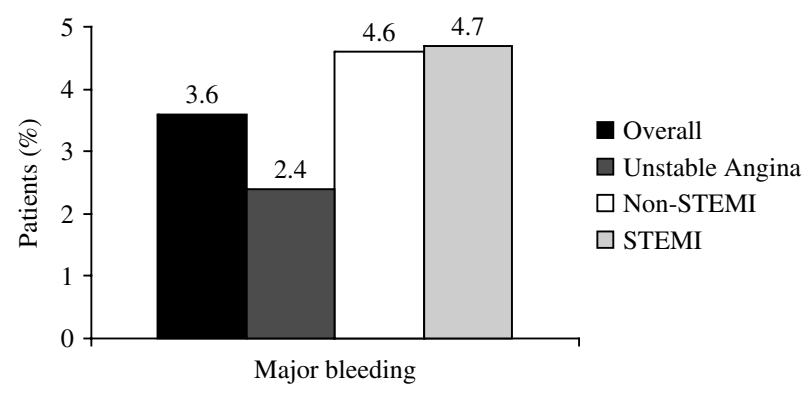

FIG. 1 Frequency of major bleeding in the Global Registry of Acute Coronary Events (GRACE). STEMI = ST-elevation myocardial infarction. Reproduced from Ref. No. 7 with permission.

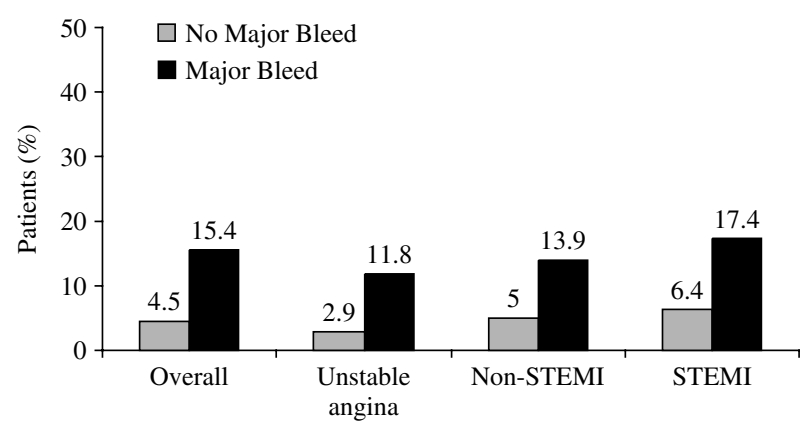

FIG. 2 In-hospital mortality according to development of major bleeding in patients with acute coronary syndromes. STEMI = ST-elevation myocardial infarction. Data from the Global Registry of Acute Coronary Events (GRACE).

with ACS, and in patients undergoing PCI. Female sex, advanced age, renal insufficiency, and history of bleeding have been consistently associated with an increased risk of bleeding, ${ }^{7}$ and with an increased risk of vascular complications after PCI. ${ }^{14,15}$ In addition, renal dysfunction has been identified as an important correlate of adverse outcomes after percutaneous and surgical cardiac procedures. The postulated mechanisms of the association between renal insufficiency and an increased risk of bleeding include platelet dysfunction, ${ }^{16}$ impaired clearance of unfractionated heparin and of low molecular weight heparin, ${ }^{17,18}$ and additional abnormalities in the coagulation cascade. In addition to these baseline comorbidities, pharmacological and mechanical therapeutic interventions, in particular, the use of thrombolytic agents GP IIb/IIIa receptor blockers, and of invasive procedures, have been previously identified as independent factors associated with major bleeding. ${ }^{7}$ Human error and equipment limitations might play a further role in the development of major bleeding in patients undergoing PCI. ${ }^{19}$ Finally, the recent introduction of newer antithrombotic agents in the management of patients with ACS, and of patients undergoing PCI appears to have a

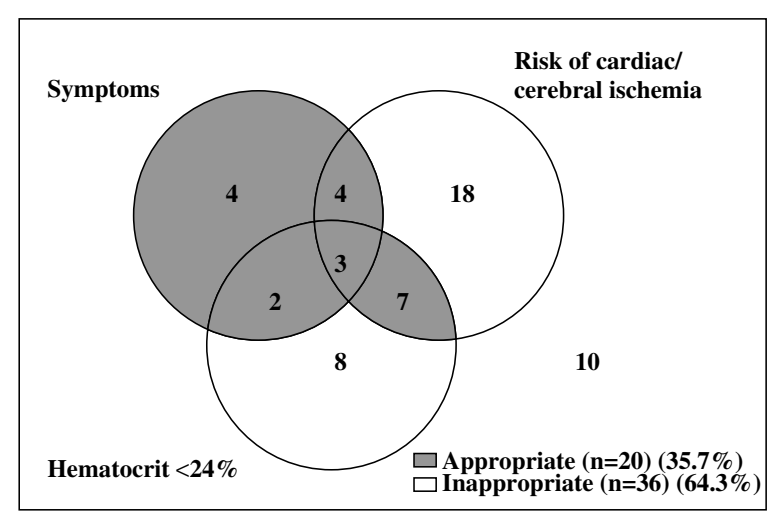

FIG. 3 Venn diagram illustrating the number of appropriate and inappropriate blood transfusions according to the criteria used in a retrospective analysis of transfusion practice after percutaneous coronary intervention in a single institution. ${ }^{23}$ In that analysis, a hematocrit $<24 \%$ was included as an additional appropriate trigger for blood transfusion in asymptomatic patients at risk of ischemia. Transfusions that fulfill only one criterion are enclosed by one circle. Transfusions that fulfill two criteria are enclosed by three circles, whereas transfusions that fulfill three criteria are enclosed in all circles. Transfusions that do not meet any criteria are outside the circles, while appropriate transfusions are enclosed in the shaded area. ${ }^{23}$

promising role in reducing the risk of major bleeding among these patient groups. ${ }^{20,21}$

The identification of risk factors for major bleeding and for blood transfusion allows the development of risk-adjustment models that can be used to identify patients at higher risk of bleeding, and for the assessment of the effectiveness of quality improvement efforts aimed toward reducing bleeding complications and transfusions.

\section{Guidelines for Blood Transfusion}

In 1992, the American College of Physicians proposed guidelines for blood transfusion. ${ }^{22}$ According to those guidelines, the decision to administer a blood transfusion to a patient should not be based on a hemoglobin trigger, but rather on a patient's symptoms and on the risk of ischemic complications from acute anemia. In the setting of acute anemia secondary to blood loss, crystalloid infusions should be tried first, and single units should be transfused rather than what has been anecdotally the standard of 2 units of packed red blood cells. In addition, the decision to proceed with blood transfusion should be based on the presence of symptoms defined as transient ischemic attack, syncope, chest pain, and sinus tachycardia, and on the basis of a patient's risk of ischemic complications from the acute blood loss. A patient's risk is defined as the presence of unrevascularized coronary artery territory, valvular heart disease, and congestive 


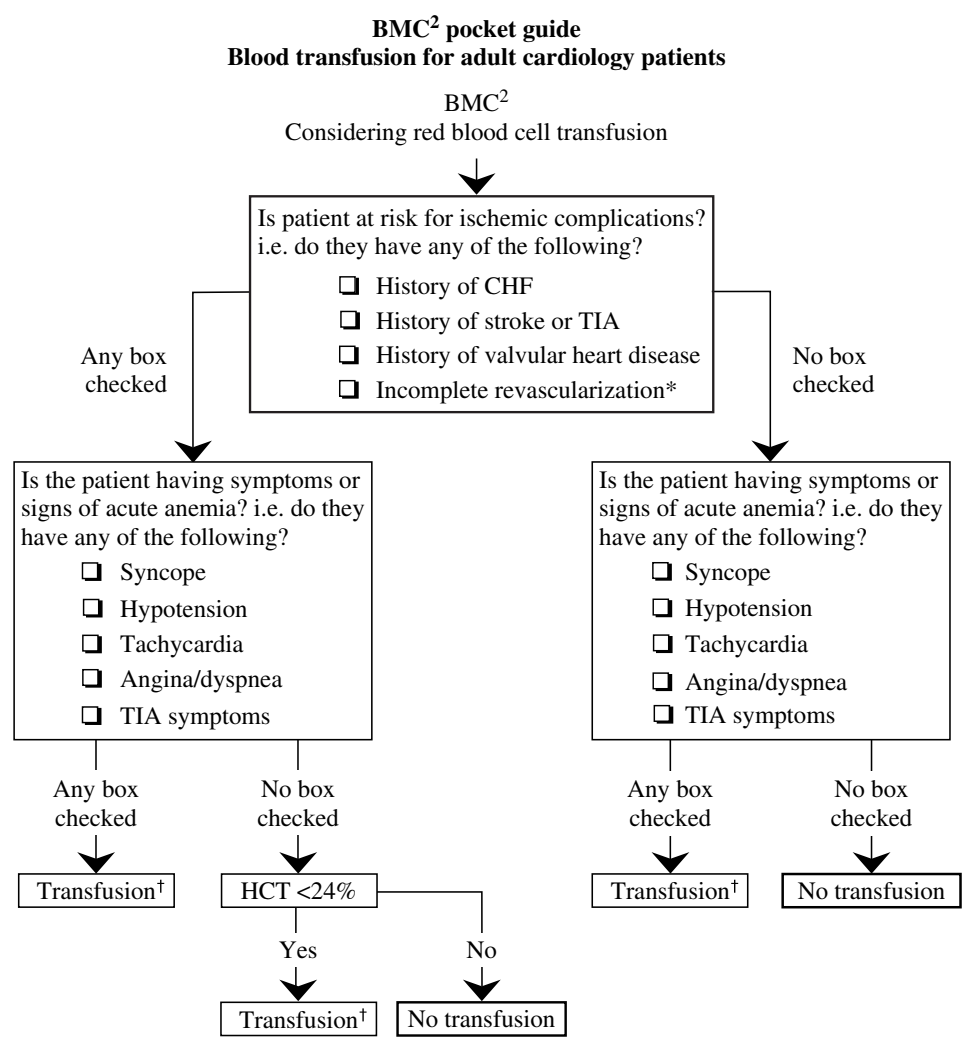

FIG. 4 Clinical algorithm with guidelines for blood transfusion developed to aid the decision-making process for administering blood transfusion. The other side of the index card includes references and a brief explanation with the rationale for using guidelines for blood transfusion. The algorithm is printed on a laminated index card that is distributed to each physician rotating on the cardiology service. ${ }^{*}$ Greater than $50 \%$ stenosis in any major epicardial artery or branch. $†$ Consider use of one unit red blood cells, which should raise the hematocrit by $3 \%$. Abbreriations: $\mathrm{BMC}^{2}=$ Blue Cross Blue Shield of Michigan Cardiovascular Consortium; $\mathrm{CHF}=$ congestive heart failure; HCT = hematocrit; TIA $=$ transient ischemic attack. Source: University of Michigan Interventional Cardiology Service.

heart failure. According to the guidelines, in the absence of risk factors and of symptoms, patients should not be given a blood transfusion regardless of their hemoglobin level.

Few studies have attempted to assess appropriateness of blood transfusion according to these criteria. ${ }^{23,24}$ In one such study, ${ }^{23}$ transfusion events in 628 patients undergoing PCI were evaluated retrospectively. Blood transfusions were administered after $8.9 \%$ of interventions (56 of 628) and were more frequent in patients undergoing coronary stenting, in women, elderly patients, patients undergoing PCI for acute myocardial infarctions, and in patients undergoing procedures that required placement of an intra-aortic balloon pump. After application of the guidelines for blood transfusion, $64 \%$ of transfusion events could be classified as inappropriate (Fig. 3). Although the retrospective study design can be viewed as an important limitation, the results suggested that application of the American College of Physician Guidelines for blood transfusion might have the potential to reduce the frequency of blood transfusion.

\section{Reduction of Blood Transfusion Rates as a Model for Quality Improvement}

In light of the factors described above, and the fact that in analyzing blood transfusion practices in a regional PCI consortium including five hospitals, a relatively high transfusion rate was observed at the University of Michigan when compared with the consortium. In 1998, the University of Michigan Interventional Cardiology Service decided to set blood transfusion as a target for quality improvement.

An algorithm with guidelines for blood transfusion was, therefore, developed and included in a single index card (Fig. 4). The index card included on one side the algorithm to aid the decision-making process for administering blood transfusion, and on the other side, the rationale and supporting data for the guidelines. The card was circulated among the interventional cardiology staff, the general cardiology staff and trainees, and additional reminders were provided on a monthly basis. In addition, detailed quarterly reports were provided to each individual interventional cardiologist. The reports included 
three columns with aggregate consortium data, aggregate hospital data, and individual operator data. Each column included comorbidities, demographic data, procedural data, and outcome data of all patients undergoing PCI. The purpose of the report was to provide feedback to individual operators, and to allow operators to compare their practices with the hospital practice and the consortium practice.

As shown in Figure 5, in 1998, the transfusion rate was significantly higher in the index hospital when compared with the consortium. Over the following 3 years, the frequency of blood transfusions in our hospital decreased progressively and, in 2001, the transfusion rate was the lowest within the consortium (Fig. 5).

\section{Conclusion}

The past decade has been characterized by an emphasis on improving quality of care of patients with ACS, and of patients undergoing cardiovascular procedures. In addition, several studies have brought attention to the importance of avoiding bleeding, and to the controversy surrounding the relationship between blood transfusion and an increased risk of short- and long-term mortality. Application of a continuous quality improvement approach such as the one used in our evaluation, with the inclusion of benchmarking and of available guidelines, appears a promising approach to reducing the frequency of blood transfusion in patients with ACS, and in patients undergoing PCI. Further studies are needed to assess the effectiveness of this approach on a larger scale.

\section{Acknowledgements}

This work was funded by a grant from Blue Cross Blue Shield of Michigan.

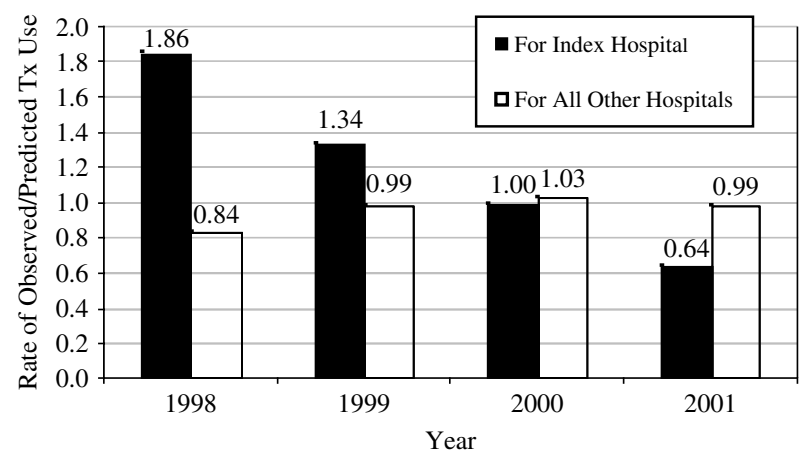

FIG. 5 Standardized transfusion ratios for the index hospital versus all other hospitals during the 4 years of follow-up. The data represent the ratio of observed over predicted transfusion rates. Predicted transfusion rates were estimated using multivariate logistic regression modeling. A ratio above 1 indicates that the observed rate is higher than predicted. $T x=$ transfusion.

\section{References}

1. Bovill EG, Terrin ML, Stump DC, Berke AD, Frederick M, et al.: Hemorrhagic events during therapy with recombinant tissue-type plasminogen activator, heparin, and aspirin for acute myocardial infarction. Results of the Thrombolysis in Myocardial Infarction, Phase II Trial. Ann Intern Med 1991;115:256-265

2. Bovill EG, Tracy RP, Knatterud GL, Stone PH, Nasmith J, et al.: Hemorrhagic events during therapy with recombinant tissue plasminogen activator, heparin, and aspirin for unstable angina Thrombolysis in Myocardial Ischemia, phase IIIB trial. Am J Cardiol 1997; 79:391-396

3. Tcheng JE: Clinical challenges of platelet glycoprotein IIb/IIIa receptor inhibitor therapy: Bleeding, reversal, thrombocytopenia, and retreatment. Am Heart J 2000;139(2):S38-S45

4. Moscucci M, Rogers EK, Montoye C, Smith DE, Share D, et al.: Association of a continuous quality improvement initiative with practice and outcome variations of contemporary percutaneous coronary interventions. Circulation 2006;113:814-822

5. Schreiber GB, Busch MP, Kleinman SH, Korelitz JJ: The risk of transfusion-transmitted viral infections. The Retrovirus Epidemiology Donor Study. N Engl J Med 1996;334:1685-1690

6. Alter HJ, Nakatsuji Y, Melpolder J, Wages J, Wesley R, et al.: The incidence of transfusion-associated hepatitis $\mathrm{G}$ virus infection and its relation to liver disease. $N$ Engl J Med 1997;336:747-754

7. Moscucci M, Fox KA, Cannon CP, Klein W, López-Sendón J, et al.: Predictors of major bleeding in acute coronary syndromes: The Global Registry of Acute Coronary Events (GRACE). Eur Heart $J$ 2003; $24: 1815-1823$

8. Hébert PC, Wells G, Blajchman MA, Marshall J, Martin C, et al.: A multicenter, randomized, controlled clinical trial of transfusion requirements in critical care. Transfusion Requirements in Critical Care Investigators, Canadian Critical Care Trials Group. $N$ Engl J Med 1999;340:409-417

9. Rao SV, Jollis JG, Harrington RA, Granger CB, Newby LK, et al.: Relationship of blood transfusion and clinical outcomes in patients with acute coronary syndromes. JAMA 2004;292:1555-1562

10. Kinnaird TD, Stabile E, Mintz GS, Lee CW, Canos DA, et al.: Incidence, predictors, and prognostic implications of bleeding and blood transfusion following percutaneous coronary interventions. Am J Cardiol 2003;92:930-935

11. Goodnough LT, Brecher ME, Kanter MH, AuBuchon JP: Transfusion medicine. First of two parts-blood transfusion. $N$ Engl J Med 1999;340:438-447

12. Gong MN, Thompson BT, Williams P, Pothier L, Boyce PD, et al.: Clinical predictors of and mortality in acute respiratory distress syndrome: Potential role of red cell transfusion. Crit Care Med 2005;33:1191-1198

13. Taylor RW, Manganaro L, O'Brien J, Trottier SJ, Parker N, et al.: Impact of allogenic packed red blood cell transfusion on nosocomial infection rates in the critically ill patient. Crit Care Med 2002;30:2249-2254

14. Moscucci M, Mansour KA, Kent KC, Kuntz RE, Senerchia C, et al.: Peripheral vascular complications of directional coronary atherectomy and stenting: Predictors, management, and outcome. Am J Cardiol 1994;74:448-453

15. Popma JJ, Satler LF, Pichard AD, Kent KM, Campbell A, et al.: Vascular complications after balloon and new device angioplasty. Circulation 1993;88:1569-1578

16. Schiller GJ, Berkman SA: Hematologic aspects of renal insufficiency. Blood Rev 1989;3:141-146

17. Follea G, Laville M, Pozet N, Dechavanne M: Pharmacokinetic studies of standard heparin and low molecular weight heparin in patients with chronic renal failure. Haemostasis 1986;16:147-151

18. Hory B, Claudet MH, Magnette J, Bechtel P, Bayrou B: Pharmacokinetic of a very low molecular weight heparin in chronic renal failure. Thromb Res 1991;63:311-317

19. Moscucci M, Share D, Smith D, O'Donnell MJ, Riba A, et al.: Relationship between operator volume and adverse outcome in contemporary percutaneous coronary intervention practice: An analysis of a quality-controlled multicenter percutaneous coronary intervention clinical database. J Am Coll Cardiol 2005;46:625-632

20. Lincoff AM, Bittl JA, Harrington RA, Feit F, Kleiman NS, et al., REPLACE-2 Investigators: Bivalirudin and provisional glycoprotein $\mathrm{IIb} / \mathrm{III}$ a blockade compared with heparin and planned glycoprotein IIb/IIIa blockade during percutaneous 
coronary intervention: REPLACE-2 randomized trial. JAMA 2003;289:853-863

21. Stone GW, McLaurin BT, Cox DA, Bertrand ME, Lincoff AM, et al., ACUITY Investigators: Bivalirudin for patients with acute coronary syndromes. N Engl J Med 2006;355:2203-2216

22. American College of Physicians: Practice strategies for elective red blood cell transfusion. Ann Intern Med 1992;116 403-406
23. Moscucci M, Ricciardi M, Eagle KA, Kline E, Bates ER, et al.: Frequency, predictors, and appropriateness of blood transfusion after percutaneous coronary interventions. Am J Cardiol 1998; 81:702-707

24. Ghali WA, Palepu A, Paterson WG: Evaluation of red blood cell transfusion practices with the use of preset criteria. CMAJ 1994;150:1449-1454 